\title{
NASH E OS PASTEIS
}

Alexandre Godinho Bertoncello, Alessandra Harumi Sakai Santos

Universidade do Oeste Paulista - UNOESTE, Presidente Prudente, SP. E-mail: bertoncello@unoeste.br

\section{RESUMO}

A Teoria dos Jogos e o Equilíbrio de Nash, são um dos grandes legados matemáticos do século XX, traz conceitos amplamente utilizados em todo o mundo em várias áreas do conhecimento. Porém, normalmente os exemplos e soluções da aplicabilidade vem de grandes empresas ou países. Analisamos trailers de feira-livre sob a mesma ótica, durante seis meses, para verificar se ajustes voluntários de colaboração eram utilizados entre concorrentes. Dentro da amostra foi possível dimensionar o potencial de defesa e ataque dos mesmos através da melhor utilização da função; k (capital), L (trabalho) e por consequência o lucro. Com bons olhos observou-se que os feirantes evitam a estratégia pura de ganho de mercado e praticam inconscientemente o equilíbrio de Nash, assim se conclui que há uma relação estreita entre Nash e os vendedores de pastéis.

Palavras - chave: Economia. Teoria de Nash. Pastéis. Equilíbrio. Competição.

\section{NASH AND THE DUMPLINGS}

\section{ABSTRACT}

Game Theory and Nash equilibrium, are one of the great mathematical legacy of the twentieth century, it brings concepts widely used around the world in various fields of knowledge. However, usually the examples and solutions of their applicability come from large companies or countries. We analysed trailers of open-air market with the same point of view, for six months we checked if volunteer adjustments of collaboration were used among competitors. Within the sample we could see the potential of defence and attack of the players through the better use of the function; K (capital), L (labour) and therefore, the profit. Nicely we noted that the players avoid the pure strategy of market gain and unconsciously practice the Nash equilibrium, hence, it is concluded that there is a close approach between Nash and the dumpling's sellers.

Keywords: Economics. Nash's theory. Dumpling. Balance. Competition.

\section{INTRODUÇÃO}

Em um mundo decorrente de grandes transformações é mister compelir esforços para compreender a dinâmica coeva da economia, mais precisamente perquirir a influência da economia em qualquer processo de compra e venda. A apreciação crítica de tendências mercadológicas juntamente com a concentração do mercado poderão propiciar uma análise encorpada acerca da economia.

Grandes conflagrações em múltiplos campos intelectuais da matemática pura à economia prática, foram explorados por um lustroso húngaro, John von Neumann. Este por sua vez convicto por ter descoberto uma técnica metodológica que "solucionava" a economia.

Strathern (2003, p.7), afirma que John von Neumann seu novo método radical, que chamou de teoria dos jogos. [...] mostrava como eliminar para sempre a incerteza econômica. Aos seis anos era capaz de ler uma vez uma página do catálogo telefônico de Budapeste e repeti-la imediatamente de memória. Aos oito anos, conseguia dividir de cabeça dois números de oito dígitos.

Neumann contribuiu para a melhoria do modelo da teoria dos jogos, que podiam ser aplicadas as diversas situações como, estratégia nuclear, divórcio ou em pôquer, e casamento. $\mathrm{O}$ autor coloca sua utilização em qualquer atividade humana que envolvesse conflito.

Segundo o autor há dois tipos de jogos, o primeiro chamado "ruled-based games" onde os participantes interagem com regras de comportamento pré-definidas ou subentendidas. 
Apesar da tensão da guerra fria nenhuma das superpotências fez um ataque nuclear ${ }^{1}$.

A segunda modalidade são os jogos

"freewheeling games" ou de livre comportamento, onde os jogadores interagem sem nenhuma restrição ou regras. Como em uma guerra tradicional onde os exércitos usam todas as ferramentas disponíveis para vencer.

Neumann acreditava que o mercado poderia ser representado por uma combinação dos dois tipos de jogos acima, e assim na abordagem clássica se dividia o comportamento empresarial como: cooperativo e não cooperativo.

Sendo o primeiro, classificado como jogos de soma "não zero", ou seja, neste os participantes tomariam decisões que de alguma forma adicionaria valor global ao ambiente econômico. O chamado tipo "win-win" acontece quando os movimentos de ajuda mútua ocorrem, seja de forma consciente através de alianças ou inconsciente por acomodação ou amadurecimento do mercado.

Por outro lado, nos jogos não cooperativos pressupõem a luta. O modelo da teoria dos jogos tenta prever o comportamento dos jogadores racionalizando os movimentos através da assimetria de informações, tendo como único objetivo a proteção. O jogador inteligente faria movimentos conforme seu grau de informação.

Assim verifica-se que a abordagem de Von Neumann à teoria dos jogos foi fundamentalmente cooperativa, sua soma nãozero envolvia colaboração, produzindo situações ganhar-ganhar e coisas semelhantes, (STRATHERN 2003).

Em outubro de 1949, John Nash, um ambicioso jovem de 21 anos formado em matemática, procurou Von Neumann. Nash era um brilhante matemático, uma pessoa competitiva e questionador. Nash leu a Teoria dos jogos e o comportamento econômico nos anos que se seguiram à sua publicação em 1949. Logo, começa a história de John Nash, o qual está diretamente ligado à esta pesquisa. Nash adentrou a teoria dos jogos e se aprofundou para conhecer a dinâmica econômica.

Ainda Strathern (2003, p. 196), acrescenta que:

\footnotetext{
${ }^{1}$ Guerra fria aconteceu no período entre 1949 e 1990 onde os Estados Unidos e a União Soviética se desafiavam com bombas nucleares.
}

A teoria dos jogos, porém, compreendia competição, mas também se dava conta de que o mercado era uma instituição social que envolvia colaboração. Em conformidade com seu caráter, Nash chegou à teoria dos jogos a partir da direção diametralmente oposta. Ele vivia num mundo em que não havia verdadeira comunicação. $\mathrm{Na}$ luta pela supremacia, pelo ganho ótimo, cada um agia por si. Jogos colaborativos eram mera conveniência. A situação de jogo era essencialmente não-colaborativa. Nash foi o primeiro a distinguir jogos cooperativos e nãocooperativos.

Compreendeu que os jogos frequentemente envolviam uma combinação de ambos. Os jogadores vão colaborar entre si por seu próprio ganho, mas tendem a romper esse arranjo/acordo quando isso é vantajoso para eles. [...] A distinção feita por Nash abriria a teoria dos jogos para uma gama muito maior de aplicações: aqui estava como o mundo real da economia funcionava.

Nash, segundo o autor, não tinha contatos comunicativos com outras pessoas, vivia isolado em um mundo da teoria. Estudava a interação dos jogos, a ponto que fez descobertas que levaram a ampliar a aplicabilidade da teoria dos Jogos.

O conceito de equilíbrio, segundo ele podia se manifestar sob situações nãocolaborativas da teoria dos jogos. Assim como no pôquer, onde todos os jogadores devem agir simultaneamente. No mercado a situação é precisamente análoga, todos os competidores devem agir ao mesmo tempo, sem ter conhecimento da estratégia que os demais vão 
adotar. Nash calculou como cada jogador pode ter uma resposta ótima. Quando todos os jogadores adotam sua melhor resposta, o jogo ou mercado econômico - chega a uma situação ótima.

Assim alcança-se o equilíbrio. Nenhum jogador poderia melhorar sua situação usando outra estratégia, dadas às estratégias adotadas pelos outros jogadores. Há uma situação de mercado em que todos os competidores podem, com suas diferentes estratégias, adotar a estratégia correta para eles.

Esse era o equilíbrio que Von Neumann considerou trivial. Neumann acreditava que a informação ou ausência dela determinava o equilíbrio. Nash desenvolveu artigos e começou a crescer e se destacar em suas teorias, (STRATHERN 2003).

Conforme o autor Nash começa a se desenvolver em suas pesquisas e isso o instigou a buscar com afinco os resultados referentes ao equilíbrio que Von Neumann rejeitou. A contribuição dos dois matemáticos foi relevante, porém o equilíbrio de Neumann se mostra mais refinado matematicamente e com pouca aplicabilidade, por outro lado o equilíbrio de Nash foi difundido em todo mundo e em várias áreas.

\section{DISCUSSÃO}

O equilíbrio de Nash quando atingido, proporciona aos participantes do jogo um resultado otimizado das possibilidades. Isso quer dizer que dentro de todas as probabilidades os participantes obtêm o máximo possível dentro das combinações possíveis. Isso ocorre porque cada jogador escolhe uma ação com base nas ações tomadas por outros jogadores. Vitorino Filho, Sacomano Neto e Silva (2011) afirmam que: Para definir a solução do jogo é importante eliminar ações que um jogador definitivamente não tomaria. Em um jogo entre dois ou mais jogadores é particularmente atraente assumir que os jogadores, procurando por modos de simplificar a situação com que se deparam, adotarão uma tática a seguir. Assume-se que os jogadores excluem de consideração ações que não são respostas ótimas para o que quer que seja que os outros façam. Um jogador que sabe que os outros jogadores são racionais pode assumir que eles também irão excluir tais ações de consideração. [...] Um problema que pode surgir quando se usa a eliminação de estratégias, para obtenção do equilíbrio de Nash é que o processo frequentemente produz uma predição muito imprecisa sobre a jogada. Onde podem haver estratégias fracamente dominadas a serem eliminadas, por exemplo: conceder os serviços com a população sendo contra. Se existe um modo óbvio de jogar, então esse modo é um Equilíbrio de Nash, pois é o que traz melhores resultados ao longo prazo, não fornecendo prejuízo a nenhum dos jogadores. Entretanto nem todo equilíbrio de Nash é um modo óbvio de se jogar. Às vezes, se os jogadores podem se comunicar antes do jogo é de interesse comum coordenar suas ações.

As colocações do autor trazem uma visão ampla sobre o equilíbrio, demonstrando que não é uma constante fácil de conseguir, muito menos de se manter. Mudanças serão necessárias ao longo do tempo, "para que ambas as partes continuem sempre ganhando nesse jogo dos recursos hídricos contra percepções e expectativas dos consumidores", (VITORINO FILHO; SACOMANO NETO; SILVA, 2011, p.4).

Através de variáveis matemáticas, Nash descobriu que é preciso imaginar o que o adversário faria diante de algumas premissas, ou seja, prever a reação do seu oponente. Apesar de complexo, o conceito de equilíbrio desenvolvido por Nash é bastante relevante ao se estudar a 
Teoria dos Jogos funciona como uma ferramenta analítica normativa e descritiva para a tomada de decisão. Tavares (apud ABBADE, 2009, p. 17) também traz o conceito de equilíbrio de Nash:

[...] como sendo
combinação de estratégias
ótimas de cada jogador, ou
seja, a melhor resposta às
estratégias dos outros
jogadores. Este conceito
está intimamente ligado ao
conceito de cooperação já
que os jogadores atuam de
forma a atingir o que
melhor para todos
Entretanto,
determinados jogos, mais de um equilíbrio pode ser identificado. Isso resulta em dificuldades metodológicas para a aplicação da teoria em realidades empresariais, inclusive no próprio processo de análise e avaliação da formação de Alianças Estratégicas. Dentre as limitações observadas na aplicação do Equilíbrio de Nash, verificase que, para que 0 equilíbrio seja alcançado são necessárias que algumas condições sejam satisfeitas. Estas condições são: (1) os participantes do jogo devem se comportar de modo perfeitamente e ilimitadamente racional; (2) não deve haver comunicação prévia ao início do jogo de modo a evitar conluios entre os players; e (3) os players devem possuir informações completas e que estas sejam de conhecimento comum de todos.

Segundo o autor, a estratégia utilizada se baseia na cooperação, onde todos os jogadores almejam um bem comum. Isso poderá ser abarcado somente se as condições precitadas pelo autor forem palpáveis de verificação. Afinal a formação de alianças estratégicas é um meio de aumentar a competitividade das empresas, o qual estão ligadas diretamente à cooperação.

Parkhe (apud ABBADE, 2009) afirma que a aliança estratégica é um ajuste voluntário de colaboração Inter organizacional, no qual é firmado para garantir que o seu parceiro não mude de ideia, ou seja, o futuro por ser incerto poderá causar mudanças de atitudes avassaladoras, podendo assim comprometer a aliança firmada entre as partes.

Abbade (2009, p.19) coloca de forma mais aprofundada que:

Através da aplicação da lógica da Teoria dos Jogos pode-se, também, prever de que forma a coalizão preferida irá afetar os demais jogadores, neste caso as demais organizações. A partir do momento em que se opta por determinada coalizão, analisa-se sob uma lógica de jogos competitivos a relação entre a própria coalizão e os outros jogadores. Sendo assim, verifica-se os possíveis resultados das coalizões analisando o jogo sob a lógica cooperativa e a influência que esta coalizão terá sob os demais jogadores adotando a lógica. Quando, na literatura, algumas tipologias de Alianças Estratégicas afirmam que se deve observar os objetivos das organizações, avaliar as possíveis opções de alianças, avaliar os possíveis fatores negociáveis e etc., utilizase a lógica da Teoria dos Jogos.

Coerentemente, a teoria dos jogos poderá ser implantada na prática pelos empresários que almejam conseguir um equilíbrio de Nash. O campo da administração necessita de estudos concretos como a teoria dos jogos. É precípuo a abertura de investigações que 
possam estudar esta teoria de forma mais profunda, identificando suas contribuições para a administração, mais especificadamente a administração estratégica.

Tratou-se nessa pesquisa da administração estratégica de pequenas empresas nas feiras livres na cidade de Presidente Prudente, identificando o pastel como o produto mais popular entre aqueles que não dependem diretamente de fatores climáticos para serem ofertados. Com a facilidade de fornecimento de matérias primas para a produção do bem, 0 preço natural pode ser respeitado e com a grande demanda, garantida por um hábito prudentino, com essas premissas pode-se analisar o comportamento estratégico dos jogadores.

É de senso comum que as pequenas empresas negligenciam estratégias de longo prazo por questões estruturais ligadas aos desafios econômicos imediatos (SEBRAE, 2015). Outro grande desafio é o fato que a literatura traz poucos estudos de microeconomia aplicada em PMEs apesar da sua grande importância no tecido social brasileiro como demonstra a tabela 1.

Tabela 1. Empresas na economia

\begin{tabular}{|l|c|c|c|}
\hline \multicolumn{1}{|c|}{ PAÍSES } & $\begin{array}{c}\text { PARTICIPAÇÃO NOS } \\
\text { ESTABELECIMENTOS } \\
\text { (\%) }\end{array}$ & $\begin{array}{c}\text { PARTICIPAÇÃO NOS } \\
\text { EMPREGOS } \\
\text { (\%) }\end{array}$ & $\begin{array}{c}\text { PARTICIPAÇÃO } \\
\text { NO PIB } \\
\text { (\%) }\end{array}$ \\
\hline Itália & 99,40 & 68,50 & 55,60 \\
\hline Grécia & 99,50 & 75,30 & 55,60 \\
\hline Espanha & 99,50 & 63,20 & 50,60 \\
\hline Portugal & 99,30 & 65,20 & 46,30 \\
\hline França & 98,80 & 45,50 & 39,70 \\
\hline Brasil & 99,10 & 52,20 & 20,00 \\
\hline
\end{tabular}

Fonte: As Pequenas Empresas na economia SBA Fact Sheet 2009 - European Commissiona Enterprise and Industry e Ministério do Trabalho e Emprego.

Desta forma "colocar sobre a mesa" a aplicabilidade das teorias da administração com um modelo de microeconomia aplicada, de importância mundial, como o equilíbrio de Nash, coopera de forma significativa na manutenção e no aumento de capital de pequenos empreendimentos e o desenvolvimento regional.

A complexidade das escolhas administrativas de uma banca de pasteis em uma feira livre em Presidente Prudente é similar a qualquer outra empresa de pequeno e médio porte em qualquer lugar no Brasil, com dificuldades e dilemas parecidos do ponto de vista do limite entre ataque e defesa dos concorrentes.

Hubbard (2008) demonstra que caso haja, por parte das empresas, o único objetivo de criar ativos através da competição e ganhos de mercado, o aumento dos custos cria um "holdup" que anula os ganhos iniciais. Desta forma compreender as decisões integradas do mercado é uma delicada missão, mas com elementar grau de importância.

Ainda segundo Hubbard a maioria das empresas de pequeno porte tem proprietários centralizadores, nos três trailers pesquisados também foi constatado perfil similar principalmente no que diz respeito ao fluxo de caixa das empresas, mas a grande maioria das empresas segundo o autor de certa forma compreendem o posicionamento de mercado e não tem uma estratégia de ganho de mercado ou de guerra de preços.

Encontramos um cenário parecido com o descrito por Hubbard, nosso estudo de caso empírico busca compreender as decisões de acomodação de mercado que acontecem mesmo que alguns elementos econômicos clássicos demonstrem margem para luta de mercado, tais como: custo marginal (CM), produção marginal de mão de obra (PMgn) e de capital (PMgk). 
O padrão de comportamento empresarial, normalmente definido por ações do passado, tem reflexos nas estratégias de dissuasão de entrada da empresa e dos concorrentes criando assim padrões razoavelmente previsíveis segundo Gruca e Sudharshan (1995).

Varian (2003) demonstra que muitas vezes, empresas mantém a chamada "estratégia pura" de mercado, ou seja, tem uma visão simplista do seu posicionamento no mercado. Busca o ganho de mercado a qualquer custo e por consequência impede o equilíbrio de Nash diminuindo a lucratividade de todos os participantes do mercado. E em algumas vezes provoca a sua falência ou a falência de uma parte do setor.

Desta forma, as observações de Varian, Gruca e Sudharshan norteariam esta pesquisa, caso fosse encontradas empresas de estratégia pura, como elas estariam inseridas no mercado ou por outro lado, aqueles que fossem encontradas com padrões razoáveis de comportamento, qual seria o benefício ótimo da oferta, independente da sua fatia de mercado.

É evidente que o fato de não praticar uma guerra de preço, pode estar ligado a outros fatores de produção que não foram abordados nesta pesquisa, isso porque empregou-se apenas 1 dos 4 Ps.

O Mix de Marketing conhecido como os quatro $\mathrm{P}^{\prime} \mathrm{s}$, do Marketing que são: product, price, place e promotion, são descritos por Romero (2012, p.16): comunicação, estão as variáveis propaganda, promoção de vendas, venda pessoal e display, também contempladas por Borden.

Para o autor, os 4 P's formam um todo, que derivam de palavras inglesas e estão interligadas entre si. Os 4 P's são o Mix de Marketing, e cada um deles são muito abrangentes, exercendo grande influência em uma organização.

Kotler e Armstrong (apud CROCCO et al., 2010), descreve os três níveis de um produto, sendo o primeiro a justificativa do por que o cliente está adquirindo o produto, o benefício central; já o segundo diz respeito a qualidade do produto, como ele é, desde suas características até a sua embalagem; $E$ por último o terceiro nível, que é o produto ampliado abrange os serviços extras, adicionais como atendimento personalizado e diferenciado. Diante disso, observa-se que os três níveis são fundamentais na oferta de um produto. O consumidor final escolhe aquele produto específico por causa de alguma necessidade, observa a qualidade do mesmo e o que é oferecido a mais, juntamente com o produto.

Correlacionando o produto em pesquisa, pastéis, com a teoria aplicada nota-se que, por ser um produto de bens não duráveis, exige do comerciante uma atenção redobrada aos três níveis de um produto. Esses níveis poderão nortear as ações do vendedor.

Outro item dos 4 P's é o Ponto, e Crocco, et al. (2010, p. 174) salienta que:

É considerado o elemento mais importante do mix do varejo e sua principal razão de sucesso. Refere-se ao lugar em que a loja será localizada, bem como para onde virão seus consumidores. A decisão de escolha de um ponto para as operações de uma loja envolve um planejamento cuidadoso, resultado de um levantamento que responde a questões como:

- De onde virão os consumidores? 
- Quantos são os consumidores potenciais?

- Quais os concorrentes que atende a área?

- $O$ que eles oferecem e não oferecem?

- O local é de fácil acesso?

- O local é adequado ao tipo de loja?

- O ponto atende as exigências legais?

Logo o autor ressalta várias questões que devem ser seriamente consideradas. Conduzindo essas colocações para área desta pesquisa tem-se que a feira é um ponto estratégico de vendas para pastéis, pois já vem de tempos o famoso pastel de feira independente de qual é o vendedor específico. No entanto, a capacidade de diferenciação de seus concorrentes, é o que forma o diferencial competitivo.

A Promoção de vendas é um aguilhoamento direto para impulsionar imediatamente a venda do produto com a geração de um maior valor. Poderá criar uma maior motivação nos clientes para comprar um produto. As empresas utilizam estratégias de promoção para poderem encantar e atrair clientes. Empresas de consumo não duráveis são as que mais usam a ferramenta de promoção.

Promover um produto não é simplesmente negociar descontos e sim construir valor junto ao consumidor. Construir a imagem e o valor da marca são fundamentais para a construção de uma clientela a longo prazo. Comunicar o valor de um produto, em especial, é promover a proliferação da mesma, e essa comunicação exige ferramentas apropriadas para cada estratégia específica, (BELCH;BELCH, 2011).

Baseado nesses argumentos entende-se que a promoção é mais que um simples desconto ou redução de valor financeiro. É a agregação de valor ao produto, para promover a sua demanda e assim a comercialização do mesmo de forma rápida e eficiente. $O$ pastel tem uma fácil aceitação no Mercado, contudo promover este produto exige a criação de um valor. É preciso não somente atrair clientes potenciais, mas sim garantir a fidelização dos mesmos.

"Quando compreendemos como se gera valor para diferentes seguimentos de consumidores, o próximo passo na elaboração da estratégia é criar uma estrutura de preços capaz de alinhar o preço ao valor entregue e minimizar o custo de atendimento." (NAGLE E HOGAN, 2007, p. 22).

Observa-se que o preço está atrelado ao produto, que por sua vez deve se levar em conta o valor que o mesmo proporciona. Deve-se ponderar o público alvo a ser atingido, bem como sua classe social e a atuação de seu concorrente, (CROCCO et al., 2010). Segundo o autor na tomada de decisão do preço é precípuo a observância de alguns critérios, os quais implicam diretamente na estratégia elaborada.

Por sua vez, Nagle e Hogan, (2007, p. 24) asseveram que:

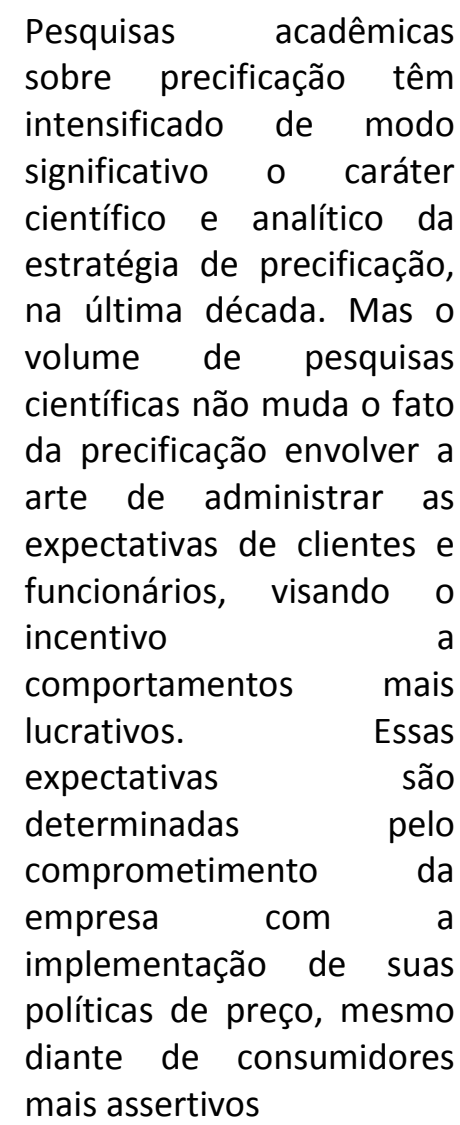

Aceda-se então que analisar e avaliar primeiramente os clientes é fator fundamental na precificação do produto. Baseado na bibliografia de autores renomados no assunto, nota-se que o preço é um item de extrema relevância no Mix de marketing de produtos.

O preço é um dos requisitos mais solicitados pelo cliente, por isso é escolhido como um dos fatores de maior impacto no resultado de uma pequena empresa. Lembrando que a fatia de mercado não depende essencialmente do preço, mas de todos os 4Ps. 


\section{METODOLOGIA}

Visitou-se 8 trailers/barracas de venda de pasteis da feira livre localizada na Avenida Manuel Goulart na cidade de Presidente Prudente do estado de São Paulo. Esta feira funciona aos sábados entre 17:00 às 21:30 horas, com a média de 6 mil visitantes por semana, segundo a Secretaria de Desenvolvimento Econômico de Presidente Prudente (Sedepp). Entre os visitados, três trailers cooperaram com a pesquisa fornecendo valores dos custos variáveis, custos fixos, preço de venda, quantidade vendida por semana, entre o período de junho de 2014 e novembro do mesmo ano, totalizando 24 semanas de acompanhamento ${ }^{2}$, nossa pesquisa tem um objetivo verificar aspectos quantitativa time series (longitudinal) com 24 observações.

Porém, houve certa resistência de abrir os dados de cada empresa para a pesquisa. Diante disso, ficou acordado que os três trailers serão identificados como Trailers A, B e C e mesmo sendo de grande valor estratégico e tendo a certeza que influencia nas vendas, a posição geográfica de cada trailer na feira não será relatada.

Outros fatores específicos da féria-livre foram observados, ela não tem infraestrutura e como consequência apresentam grande variação de público conforme a variação climática, por exemplo, é fácil imaginar que em dias de forte chuva o público diminuirá. Esse fato diminui a rentabilidade dos investimentos. Mas foi observado que não alterou o "trend do market share". Da mesma forma, outra lógica de mercado que é bem conhecida dos feirantes foi comprovada, a sazonalidade mensal demonstrouse inabalável e se confirmou em 6 meses.

Ao mesmo tempo constatou-se que as empresas pesquisadas tinham alguns pontos standard; o controle de custos contábeis de baixa representatividade, forte controle do fluxo de caixa e proprietários com anos de experiência

\footnotetext{
${ }^{2}$ Os três trailers forneceram todas as informações disponíveis e em alguns casos construíram em conjunto com os pesquisadores valores aproximados de alguns custos variáveis que em seguida foram utilizados como padrão de desempenho, por exemplo: o uso do óleo (que segundo as empresas são trocados toda a semana), a quantidade de recheio (carne, frango presunto etc.), e materiais de limpeza. Não foi objeto dá pesquisa verificar se o óleo em algum momento foi filtrado, ou a quantidade de recheio alterado ou se mudaram os padrões de higienização. Da mesma forma que o uso do capital investido, ou funcionários provavelmente não representam com fidelidade a produção marginal de mão de obra (PMgn) e de capital (PMgk), pois é sabido que vários trailers trabalham em várias feiras livres, assim, o resultado fornece uma visão estática (apenas uma feira) e não a visão dinâmica de cada empresa pesquisada.
}

com tendências centralizadoras. Os controles contábeis são ou seria a forma mais segura de observar os custos dos empreendimentos, porém em visita aos escritórios contábeis, foi observado que não havia correlação direta entre os dados contábeis e as vendas observadas no fluxo de caixa, das empresas, especificamente na feiralivre da Manoel Goulart.

Foi constatado também que as empresas que trabalham em feiras-livres normalmente fazem várias feiras durante a semana, assim apesar da feira-livre pesquisada ser a mais tradicional, estar entre as de maior público e segundo os feirantes é uma das mais "elitizadas" não há um controle contábil dividido por feiras, mas apenas um controle feito por empresa.

Dentro do recorte pesquisado, as afirmações acima levantam algumas dúvidas sobre como calcular o ponto de equilíbrio das empresas por feira-livre, além destas informações outros aspectos também nos chamaram a atenção tais como; tipo de pastel consumido em uma ou outra feira (pastéis mais caros ou baratos) e de alguma forma o grau de exigência de um ou outro público (feiras mais ou menos elitizadas) todos esses fatores de produção podem influenciar no resultado.

Apesar de não haver respostas conclusivas sobre os questionamentos acima, e o levantamento feito nos 3 trailers apontam que não há um levantamento da quantidade de sabor produzido e os custos dos pastéis são divididos usando a forma mediana de custo por todas as empresas pesquisadas, adotamos para nossa analise o mesmo modelo. $O$ custo mediano foi aplicado em todos os pasteis vendidos, assim foi também aplicado um preço de venda médio entre todos os sabores oferecidos.

Por fim caso haja variação das porções aplicadas de recheio para cada feira, a feira-livre pesquisada seria a que teríamos custos maiores e ao mesmo tempo com vendas mais significativas. Analisando estas considerações acredita-se que, caso fosse aplicada uma média ponderada por empresa e por feira os resultados não seriam dispares, pelo contrário os resultados seriam tão próximos quanto à feira da Manoel Goulart.

Essas conclusões têm embasamento estatísticos como demonstrado por Souza (2009); amostras com pequenas quantidades e, que têm entre os objetos pesquisados, um com tamanho muito superior à média, os métodos de média ponderada ou mediana trazem resultados similares. Entre os trailers, o que apresenta maior 
número de feiras livres por semana é o Trailer $\mathrm{A}$, com 4 feiras, enquanto os outros dois pesquisados fazem 3 feiras durante a semana.

Se os custos tivemos que fazer algumas considerações que podem ser consideradas de alguma forma uma arbitrage, por outro lado, o caixa por sua vez é feito por cada feira, assim foi possível verificar a quantidade vendida de pasteis por semana. Sendo um banco de dados sólido para nossa pesquisa, mas para adequar a metodologia dos custos, na busca produção marginal de mão de obra (PMgn) e de capital
(PMgk) foi utilizada também o preço médio de venda.

\section{RESULTADOS}

Durante o acompanhamento das 24 semanas o Market share ficou relativamente estável com uma liderança consolidada do Trailer $A$, tendo o Trailer $B$ em segundo posto com uma pequena, mas constante vantagem do terceiro concorrente, o trailer $\mathrm{C}$.

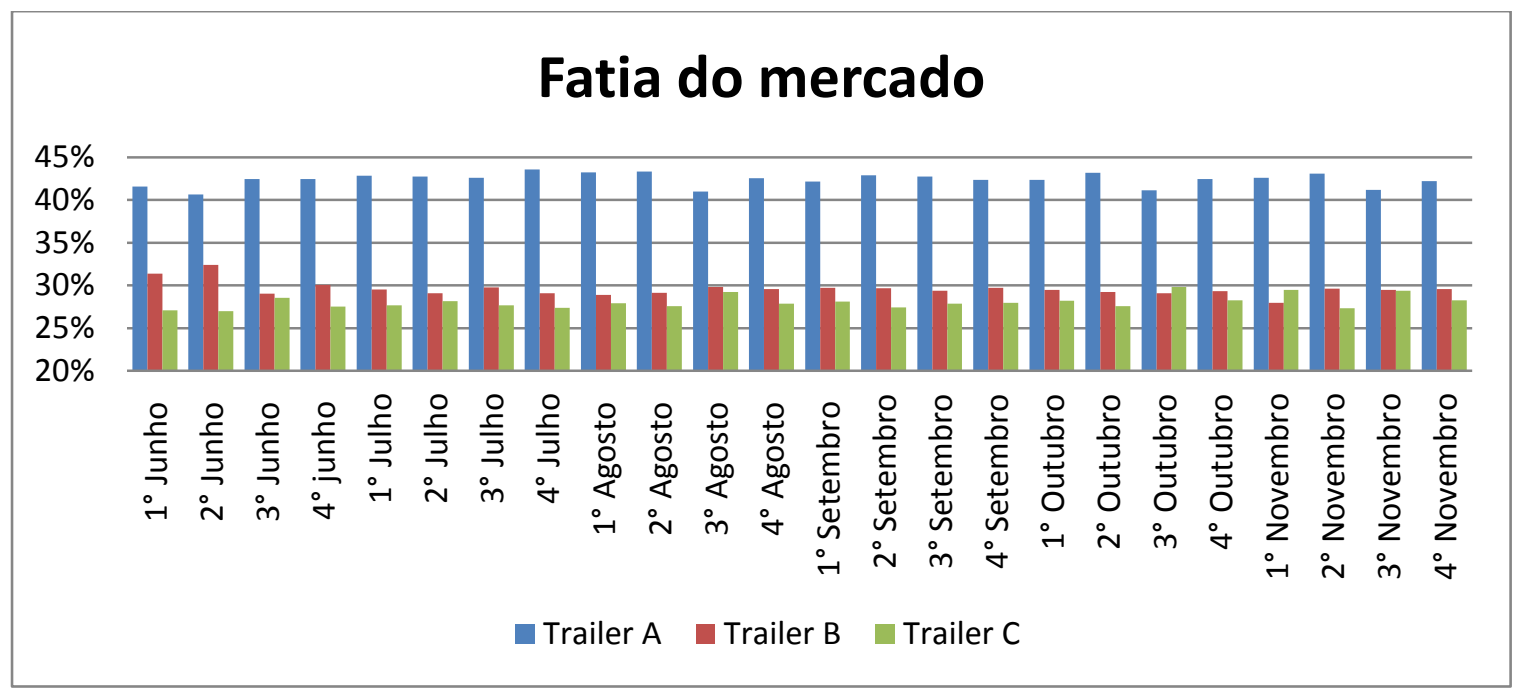

Figura 1. Fatia de Mercado

Fonte: Dados trabalhados pelos autores

Apesar de haver uma constância na posição de mercado derivada da política semelhante de comportamento, internamente foi constatado diferentes desempenhos entre os pesquisados do ponto de vista dos resultados econômicos e organização interna.

$\mathrm{O}$ Trailer $\mathrm{A}$ tem dois funcionários fixos e $\mathrm{o}$ proprietário, ou um membro da família na ausência do proprietário, sendo assim foi compultado o valor fixo dos dois funcionários integralmente. Já o Trailer B tem sempre a figura do dono presente e nas duas primeiras semanas dois funcionários e nas duas últimas apenas 1 funcionário. Enquanto o Trailer $\mathrm{C}$ trabalha com apenas um funcionário fixo e nas duas primeiras semanas o proprietário e uma pessoa da família faz a gestão do trailer, já nas duas últimas semanas vem há feira um ou outro sem um cronograma definido.

Não foi avaliado o custo de oportunidade empresarial, ou seja, o custo dos empresários ou membros da família, mas levando em considerações os outros custos foi possível constatar que apesar de ter a menor faita do mercado entre os pesquisados o Trailer $\mathrm{C}$ tem desempenho semelhante ao Trailer líder e proporcionalmente melhor.

Já O Trailer B demonstra baixo desempenho no acumulo de capital e em algumas semanas desempenho econômico negativo como no grafico seguinte. 


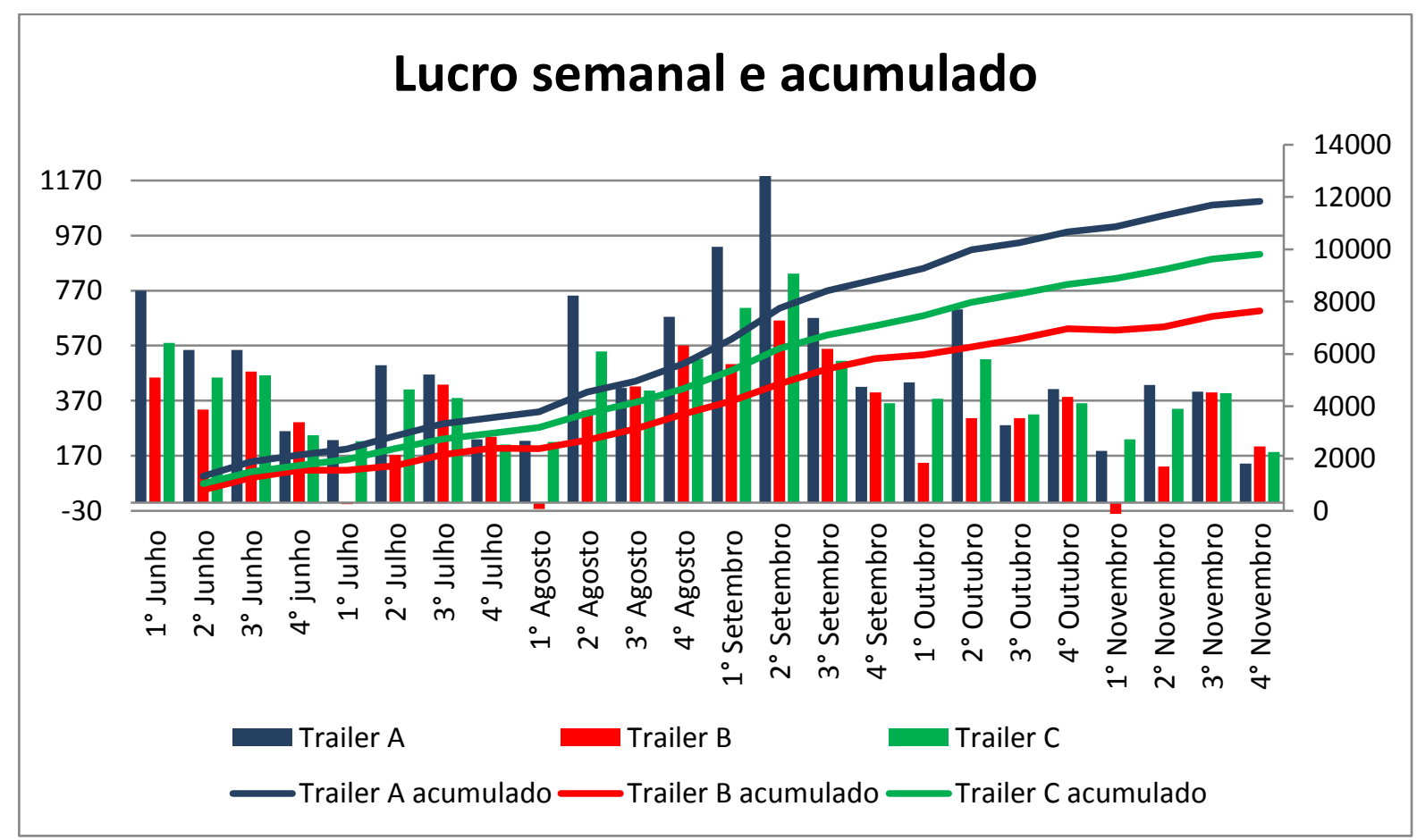

Figura 2. Lucro semanal e Acumulado

Fonte: Dados trabalhados pelos autores

Com preços de mercado muito parecidos, alguns fatores de produção diferenciam do ponto de vista econômico os participantes, são eles:

- $O$ custo marginal (CM) com diferenças significativas no comparativo do mês e também no acumulado, demonstrando a ausência de equilíbrio da empresa Trailer B e um desempenho superior do Trailer $C$ que apresenta custos menores.

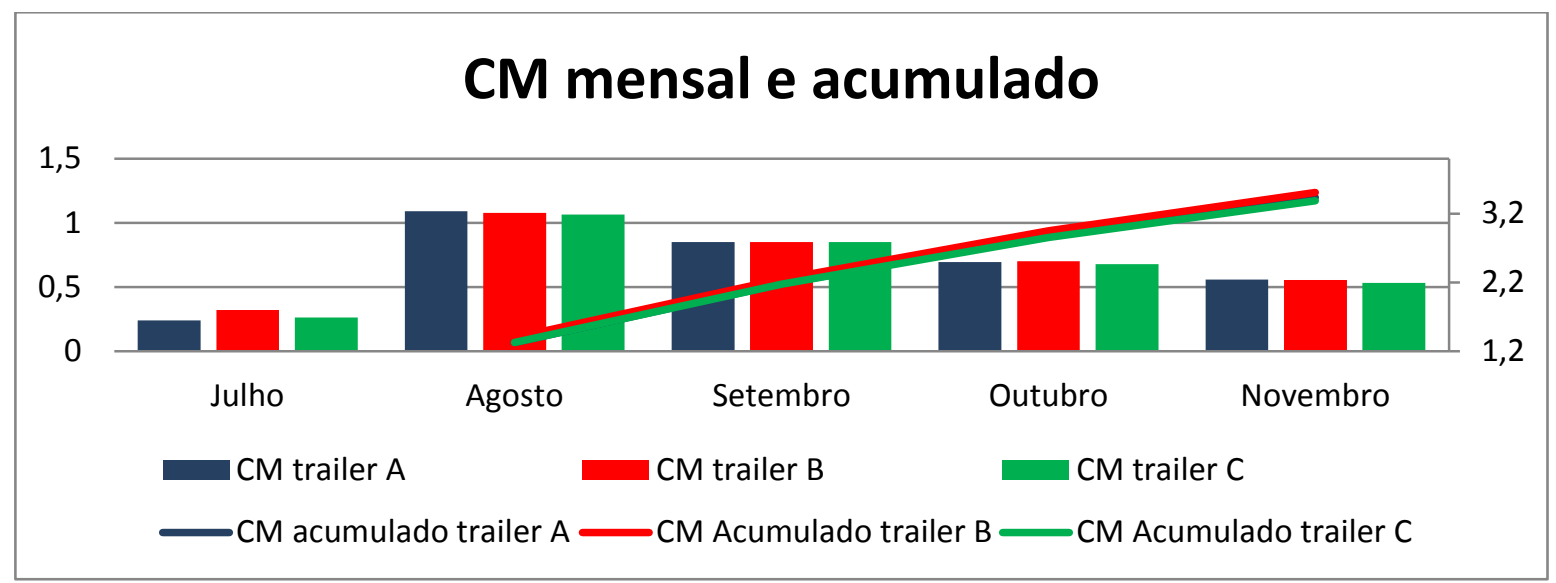

Figura 3. CM mensal e acumulado

Fonte: Dados trabalhados pelos autores

- $\quad$ Produção marginal de mão de obra, onde mais uma vez o Trailer $C$ demonstra uma superioridade na produção média de mão de obra. 


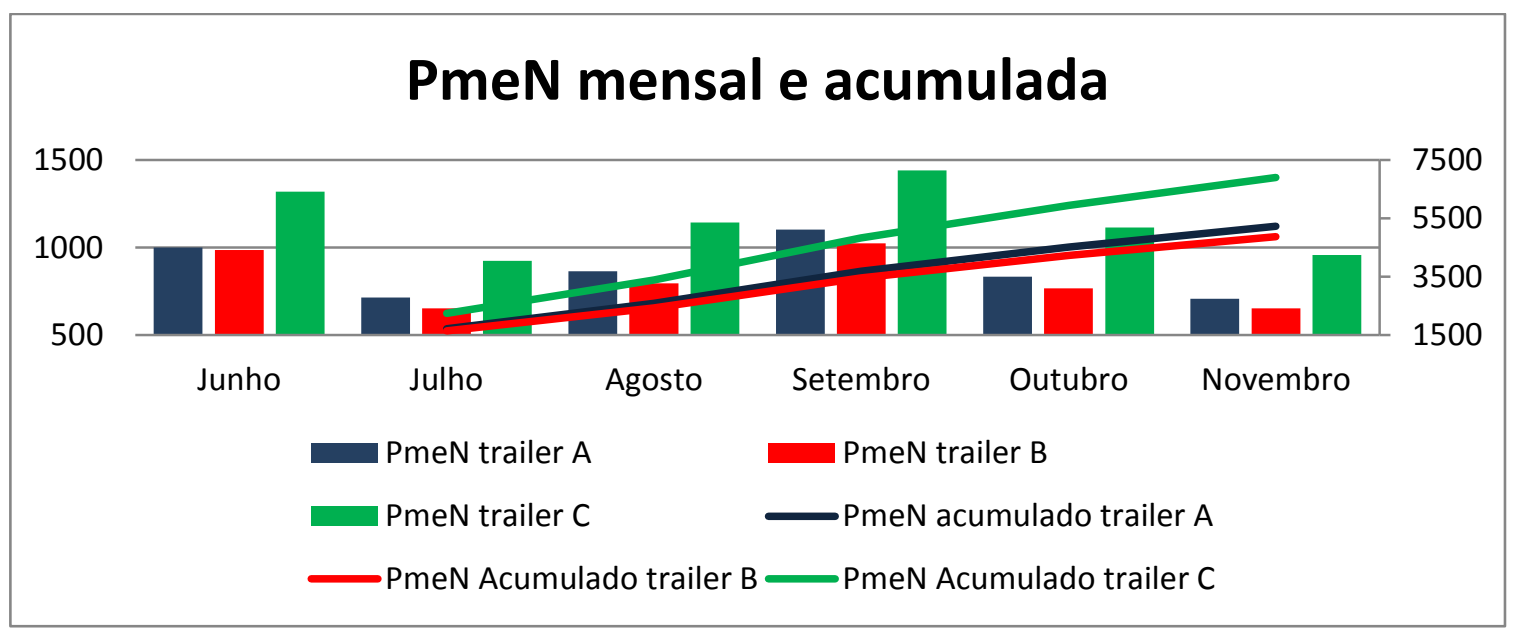

Figura 4. Produção Marginal de mão se obra

Fonte: Dados trabalhados pelos autores

- $\quad$ Por outro lado a Produção Média de Capital (PmeK) segue a mesmo formato do market share sugerindo, o Trailer C tem algum tipo de deficiência na produtividade de capital.

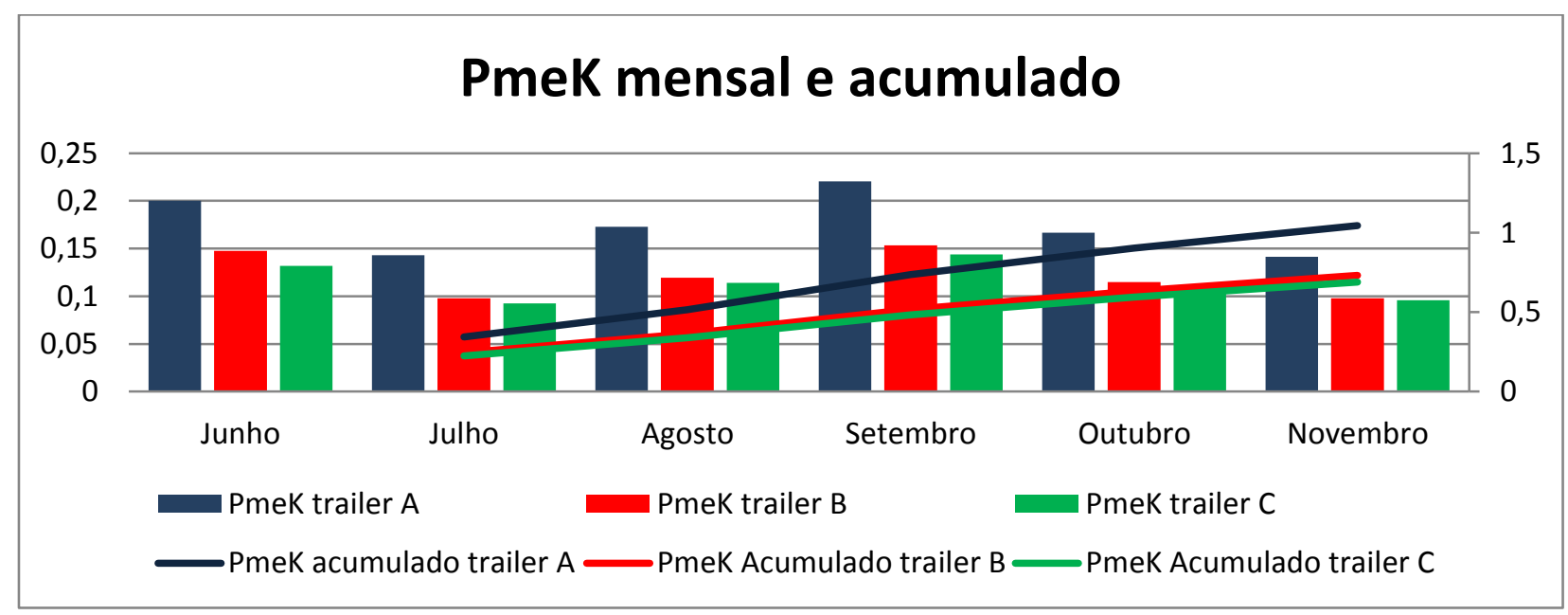

Figura 5. Produção média de capital

Fonte: Dados trabalhados pelos autores

A pesquisa realizada na feira, atrelada a teoria de Nash demonstrou que os três trailers, que comercializam os mesmos produtos, tem em certos períodos uma diferenciação nos seus resultados. Isso acontece devido a forma de atuação no mercado.

Apesar do Market share do Trailer A, ser maior que os seus concorrentes, o Trailer $C$ tem desempenho análogo á ele. Analisando-se o lucro que cada um obteve, observa-se que todos se diferem, isso também se dá devido a performance de cada um frente ao mercado.

O Trailer C poderia investir em capital para superar seus concorrentes, porém não o faz para não gerar competição entre seus adversários. Mantendo assim uma participação acomodada no mercado. Assim como o Trailer B não oferece ao mercado descontos maiores para vender mais e equilibrar a produtividade da mão de obra.

Ambos poderiam tentar abarcar o mercado de forma estratégica, mas isso colocaria em cheque o equilíbrio, e poderia prejudicar toda a economia local. Quando se utiliza na teoria dos jogos a "soma zero", nota-se que existe certo risco, pois se todos guerrearem de forma não planejada, isso poderá trazer grandes perdas ao setor.

É adotada uma estratégia diferenciada, perfilhando a estratégia apropriada para eles, sem ferir a economia. O mercado econômico está em boa conjuntura, porque os jogadores, 
Trailer A, Trailer B e Trailer C assumiram uma melhor resposta a competição.

Cada um pode ganhar em curto prazo e ter ganhos a longo prazo sem incentivar combates predatórios ente os concorrentes. Assim observa-se que há uma prática do equilíbrio de Nash entre os vendedores de pasteis na feira livre da avenida Manoel Goulart na cidade de Presidente Prudente.

Assim com a premissa pode-se concluir que a busca inerente da lucratividade e com padrões de comportamentos do mercado de venda de pasteis, foi possível verificar que padrões de comportamentos predatórios não ocorreram apesar de haver margem econômica entre os concorrentes com menor Market.

Em linhas gerais o comportamento das bancas de pasteis seguem padrões de comportamento classificados de soma não-zero da teoria dos jogos, em outras palavras os trailers de vendas de pasteis da feira livre localizada na Avenida Manuel Goulart na cidade de Presidente Prudente do estado de São Paulo praticam o equilíbrio de Nash.

\section{CONSIDERAÇÕES FINAIS}

Dentro de um determinado espaço de tempo, essa pesquisa instigou a perquirir a Teoria de Nash, onde os resultados evidenciaram, que o equilíbrio de Nash acontece. Isso é demonstrado na instabilidade de preço e de investimento do capital do feirante, mesmo com chances de conseguir ganhar mais mercado e crescer.

Apesar das limitações, de 6 meses de investigação e o objeto de pesquisa ter sido parcial (amostra 3 Trailers das 8 Trailers/bancas), obteve-se um resultado interessante que desperta o interesse à pesquisa. Curiosamente os feirantes se entendem, e aplicam técnicas refinadas de mercado, apesar da grande maioria muitas das vezes, não possuírem ensino superior, todos demonstram capacidade de administrar seus negócios.

Novas perquirições poderão ser realizadas, visto que o universo pesquisado teve como foco uma única feira livre. Mesmo percebendo durante a pesquisa, que os Trailers que vendem pastéis são os mesmo que fazem as outras feiras, isso não garante a certeza que o comportamento empresarial é o mesmo em todos os pontos de venda.

Apesar da dúvida, notou-se que os feirantes têm um comportamento de equilíbrio de mercado mais depurado. As feiras livres presumivelmente trabalham de forma mais intensa a teoria dos jogos e o equilíbrio de Nash, do que as lojas de ruas e dos Shoppings Centers da cidade.

No mesmo período da pesquisa ficou claro a ausência de novas oportunidades (espaço) na feira, demonstrando a saúde financeira dos feirantes e a vontade de permanecer na atividade, enquanto no mesmo período ficou evidente o grande "abre e fecha" de pequenas lojas. Movimento esse que deve ser investigado.

\section{REFERÊNCIAS}

ABBADE, E. B. Análise de alianças estratégicas sob a ótica da teoria dos jogos. Revista de Administração da UNIMEP, v.7, n.3, p. 24-45, set. /dez. 2009.

BELCH, G.E.; BELCH, M.A. Propaganda e promoção: uma perspectiva da comunicação integrada de marketing. 7. ed. Porto Alegre: AMGH, 2011.

BRYMAN, A. Integrating quantitative and qualitative research: how is it done? Sage Publications London, University of Leicester, v. 6, n.1, p. 97-113, 2006.

CRESWELL, J. W. E.; CLARK, V. L. P. Designing and Conducting Mixed Methods Research. California: Sage Publications, 2007.

CROCCO, L. et al. Decisão de Marketing: os 4 Ps. São Paulo: Saraiva, 2010.

FARRELL, M. J. The Measurement of productive Efficiency of Production. Journal of the Royal Statistical Society series A, v. 120, p. 253-281, 1957. http://dx.doi.org/10.2307/2343100

GRUCA T. S. E.; SUDRARSHAN, D. A. Framework for Entry Deterrence Strategy: The competitive Environment Choices and Consequences. Journal of Marketing., v. 59, n. 3, p. 44- 55, 1995. http://dx.doi.org/10.2307/1252118

HUBBARD, T. N. Firm Boundaries: empirical studies. The New Palgrave Dictionary of Economics, Second Edition, 2008.

MORTON, D. D. A nontechnical introduction. Edition Oskar Morgenstern UK:, 1970.

NAGLE, T.T.; HOGAN, J. E. Estratégias e táticas de preço: um guia para crescer com lucratividade. 4. ed. São Paulo: Person Education do Brasil, 2007.

NASH JR, J. F.. Equilibrium points in $\mathbf{N}$-person games. Princeton University Nov. 16, 1949.

ROMERO, C.B.A. Gestão do marketing no varejo: conceitos orientações e práticas. São Paulo: Atlas, 2012.

SOUZA M. J. F. Otimização combinatória. Ouro Preto: Departamento de Computação, Instituto 
de Ciências Exatas e Biológicas da Universidade de Ouro Preto, 2009.

STRATHERN, P. Uma breve história da Economia. São Paulo: Zahar, 2003.

VITORINO FILHO, V. A.; SACOMANO NETO, M.; SILVA, E. M. Processo de decisão dos consumidores quanto a concessão dos recursos hídricos no município de Capivari: um estudo a partir da teoria dos jogos. Revista de Gestão Social e Ambiental - RGSA. São Paulo, v. 5, n. 2, p. 187-210, maio/ago. 2011.

VARIAN H. R. Intermediate Microeconomics: A Modern Approach W.W. Norton \& Company NY., 2003.

Recebido para publicação em 23/03/2015

Revisado em 12/09/2015

Aceito em 04/03/2016 